\title{
NÉCTAR DE CAGAITA (Eugenia dysenterica DC.): DESENVOLVIMENTO, CARACTERIZAÇÃO MICROBIOLÓGICA, SENSORIAL, QUÍMICA E ESTUDO DA ESTABILIDADE
}

\author{
SABRINA DE FREITAS BEDETTI* \\ LEANDRO DE MORAIS CARDOSO** \\ PRISCILA ROSSINI GOMES SANTOS* \\ MARIA INÊS DE SOUZA DANTAS*** \\ HELENA MARIA PINHEIRO-SANT'ANA***
}

\begin{abstract}
O presente estudo objetivou desenvolver néctares de cagaita (Eugenia dysenterica DC.), caracterizá-los quanto aos parâmetros microbiológicos, sensoriais e químicos e verificar a estabilidade do produto durante o armazenamento. Quatro formulações de néctar contendo $20,30,40$ e $50 \%$ de polpa foram desenvolvidas e avaliadas microbiológica (coliformes totais e termotolerantes, bolores, leveduras e Salmonela spp) e sensorialmente (teste de aceitação). A formulação mais aceita foi avaliada quanto ao conteúdo de sólidos solúveis (SS), pH, acidez titulável (AT), relação SS/AT, umidade, proteínas, lipídios, carboidratos, fibra alimentar total (FAT), cinzas, carotenoides e ácido ascórbico (AA), verificando-se a estabilidade do produto armazenado sob congelamento $\left(-18^{\circ} \mathrm{C} / 90\right.$ dias) e refrigeração $\left(5^{\circ} \mathrm{C} / 72\right.$ horas). Não foi observada a presença dos micro-organismos pesquisados nas quatro formulações desenvolvidas. As formulações com 40 e $50 \%$ de polpa apresentaram maior aceitação para os atributos cor, sabor e impressão global. O néctar contendo $50 \%$ de polpa apresentou SS de $11,43^{\circ}$ Brix, pH de 3,59 e relação SS/AT de 19,37. Verificouse $(\mathrm{em} 100 \mathrm{~g})$ AT de 0,59 g de ácido cítrico; 85,75 g de umidade; $0,29 \mathrm{~g}$ de proteínas; $0,27 \mathrm{~g}$ de lipídios; $12,93 \mathrm{~g}$ de carboidratos; $0,68 \mathrm{~g}$ de FAT; $0,08 \mathrm{~g}$ de cinzas; $55,31 \mathrm{kcal} ; 0,25 \mathrm{mg}$ de carotenoides e 19,6 mg de AA. Durante o armazenamento não foram observadas alterações estatisticamente significativas nos valores de SS, AT, pH, carotenoides e AA. O néctar de cagaita atendeu as características químicas e os padrões microbiológicos estabelecidos pela legislação brasileira, alcançou boa aceitação dos consumidores e apresentou excelente estabilidade durante o armazenamento.
\end{abstract}

PALAVRAS-CHAVE: CAGAITA; FRUTO DO CERRADO; MAPA DE PREFERÊNCIA; NECTAR.

* Nutricionistas, Laboratório de Análise de Vitaminas, Departamento de Nutrição e Saúde, Universidade Federal de Viçosa (UFV), Visoça, MG (e-mail: sabrina.bedetti@ufv.br; priscila.gomes@ufv.br).

** Mestre em Ciência da Nutrição, Laboratório de Análise de Vitaminas, Departamento de Nutrição e Saúde, UFV, Visoça, MG (e-mail: leandro.cardoso@ufv.br).

*** Doutora em Ciência e Tecnologia de Alimentos, Laboratório de Análise Sensorial e Desenvolvimento de Novos Produtos, Departamento de Nutrição e Saúde, UFV, Visoça, MG (e-mail: msdantas@ufv.br).

**** Doutora em Ciência dos Alimentos, Laboratório de Análise Sensorial e Desenvolvimento de Novos Produtos, Departamento de Nutrição e Saúde, UFV, Visoça, MG (e-mail: helena.santana@ufv.br). 


\section{INTRODUÇÃO}

O Cerrado, segundo maior bioma do Brasil, apresenta ampla diversidade vegetal utilizada de diversas formas, destacando-se o aproveitamento de seus frutos. Os frutos do Cerrado apresentam potencial para a geração de renda, melhoria da alimentação humana e da qualidade de vida de famílias residentes em áreas de Cerrado, em especial daquelas em vulnerabilidade social (ALMEIDA et al., 1998; PROENÇA, OLIVEIRA e SILVA, 2000).

A cagaita (Eugenia dysenterica DC.), fruto exótico nativo do Cerrado, apresenta elevada incidência e excelentes características sensoriais (SILVA,CHAVES e NAVES, 2001). O fruto tem formato globoso e levemente achatado, e casca fina de coloração amarelo-claro. A polpa da cagaita, que corresponde a aproximadamente $90 \%$ do peso do fruto, é bastante suculenta com sabor levemente ácido. Sua polpa, fonte de vitamina $\mathrm{C}$ e folatos, apresenta baixos teores de carotenoides, proteínas, carboidratos, lipídios e cinzas (CARDOSO et al., 2011).

A exploração tecnológica da cagaita mediante desenvolvimento de produtos alimentares pode representar alternativa de significância econômica, social e nutricional para as famílias residentes em áreas de Cerrado (SILVA et al., 2008). Os produtos elaborados com o fruto podem gerar renda e elevar seu consumo, contribuindo para a promoção da saúde e prevenção de doenças carenciais.

A cagaita pode ser utilizada na fabricação de diversos produtos. No entanto, devido às suas características químicas, como $\mathrm{pH}$ ácido, baixa acidez titulável e elevada umidade (CARDOSO et al., 2011), o fruto mostra-se apto ao desenvolvimento de bebidas, especialmente o néctar. Trata-se de bebida não fermentada, destinada ao consumo direto, obtida a partir da diluição em água potável da parte comestível da fruta, ou de seu extrato, e de açúcares (BRASIL, 2009). A relação sólidos solúveis/acidez titulável (SS/AT) para os néctares deve se encontrar, em geral, na faixa de 18 a 20 com pH abaixo de 4,0. Admite-se a adição de açúcar para a correção da relação SS/AT e de ácidos, como o cítrico, para correção do pH final (PALTRINIERI e FIGUEROLA, 1997).

Diante da ausência de informações na literatura científica referentes à elaboração de néctar de cagaita, visou-se contribuir para a ampliação de dados a respeito da agregação de valor e de informação nutricional de produtos elaborados a partir dessa fruta. No presente estudo objetivou-se desenvolver formulações de néctar de cagaita, caracterizá-las quanto aos parâmetros microbiológicos, sensoriais, químicos e avaliar a estabilidade do produto ao longo do armazenamento.

\section{MATERIAL E MÉTODOS}

Este estudo foi desenvolvido nos Laboratórios de Análise Sensorial e Processamento de Novos Produtos; Higiene dos Alimentos; Análise de Alimentos e Análise de Vitaminas, localizados no Departamento de Nutrição e Saúde da Universidade Federal de Viçosa (UFV).

O projeto de pesquisa foi aprovado pelo Comitê de Ética em Pesquisa com Seres Humanos da UFV (Of. Ref. nº 0161/2010/Comitê de Ética).

\subsection{MATÉRIA-PRIMA}

Para a elaboração das formulações de néctar foram utilizados frutos de cagaita (Eugenia dysenterica DC.), procedentes do município de Curvelo (MG), sacarose e água mineral adquiridos no município de Viçosa (MG).

\subsection{EQUIPAMENTOS}

Para a elaboração dos néctares, realização das análises microbiológicas, químicas, extração de carotenoides e vitamina $\mathrm{C}$, e preparo da fase móvel foram utilizados os seguintes equipamentos: 
processador doméstico de alimentos (Philips-Walita, R17625), balança semi-analítica (Gehaka, BG 2000), pHmetro (Hexis, UB10), refratômetro digital de bancada (Instrutherm, RTP-45), banho-maria (Fanem, 102), estufa de cultura (Fanem, 002-CB), estufa (DeLeo), liofilizador (Liobras, LP510), extrator Soxhlet (Eletrothermo, 500WX), mufla (Quimis, 318), destilador de nitrogênio (Solab), bloco digestor (Gerhardt, Kjeldatherm), microtriturador (Marconi, MA 102), bomba de vácuo (Fanem, CA), centrífuga (Excelsa Baby II, com cruzeta angular 4 × $100 \mathrm{~mL}$, Fanem, 206-R), centrífuga microprocessada (Quimis, Q222EM), agitador magnético (Marconi, MAO93), estufa (Brasdonto, M4), estufa (Nova Ética), balança analítica (Gehaka, AG 200), espectrofotômetro (Thermo Scientific, Evolution 60S), sistema de filtração para fase móvel (All Glass), sistema de ultrapurificação de água (Millipore, Direct Q UV 3) e degaseificador ultrassônico (Odontobrás, modelo T-14).

Realizou-se a análise de carotenoides e vitamina $\mathrm{C}$ em sistema de cromatografia a líquido de alta eficiência (CLAE) (Shimadzu, SCL 10AT VP) constituído de bomba de alta pressão (Shimadzu, LC-10AT VP), injetor automático com alça de amostragem de $50 \mu \mathrm{L}$ (Shimadzu, SIL-10AF) e detector de arranjo de diodos (DAD) (Shimadzu, SPD-M10A). O sistema CLAE foi controlado pelo software Multi System, Class Vp 6.12 (SHIMADZU CORPORATION, 2000).

\subsection{REAGENTES E OUTROS MATERIAIS}

Nas análises microbiológicas foram usados os seguintes meios de cultivo: Ágar Batata Dextrose (PDA), Ágar Salmonella-Shigella (SS), Ágar Verde Brilhante (BG), Caldo Selenito-Cistina e Caldo Lactosado (Merck, Brasil); Caldo Lauril Sulfato Triptose - LST (Vetec, Brasil) e Caldo Rappaport (Acumedia).

Para a realização das análises químicas e preparo dos extratos de carotenoides e vitamina $\mathrm{C}$ foram utilizados os seguintes reagentes grau analítico: fosfato de sódio monobásico $\left(\mathrm{NaH}_{2} \mathrm{PO}_{4}\right)$ (Synth, Brasil); éter de petróleo, acetona e sal etilenodiaminotetraacético (EDTA) (Proquímios, Brasil); cloreto de sódio, ácido metafosfórico (AMP) e ácido acético glacial (Vetec, Brasil); sulfato de sódio anidro (Impex, Brasil) e ácido sulfúrico $\left(\mathrm{H}_{2} \mathrm{SO}_{4}\right)$ (Mallinckrodt, USA).

Para a análise de carotenoides e vitamina $C$ no néctar foram usados reagentes grau HPLC: acetona, acetato de etila, metanol e acetonitrila (Tedia, Brasil). A água ultrapura foi produzida em sistema de ultrapurificação de água. Para a filtração das amostras utilizaram-se papel de filtro $\mathrm{n}^{\circ} \mathrm{JP} 41 \mathrm{~J}$. (Prolab, Brasil), seringas descartáveis esterilizadas de $3 \mathrm{~mL}$ (TKL, China) e unidades filtrantes HV Millex, em polietileno, 0,45 $\mu \mathrm{m}$ de porosidade (Millipore, Brasil).

O padrão de ácido L-ascórbico foi adquirido da Sigma-Aldrich ${ }^{\circledR}$ (Alemanha). Os padrões de $\alpha$-caroteno e $\beta$-caroteno foram isolados de extrato concentrado de cenoura e os de $\beta$-criptoxantina e licopeno de extratos de mamão e tomate, respectivamente, por cromatografia em coluna aberta (RODRIGUEZ-AMAYA, 1989).

\subsection{OBTENÇÃO DA POLPA E ELABORAÇÃO DOS PRODUTOS}

Os frutos da cagaita utilizados na elaboração dos néctares foram adquiridos de pequenos produtores rurais, nos meses de outubro e novembro de 2010. No Laboratório de Análise de Vitaminas, os frutos íntegros e com maturação completa (casca 100\% amarela e textura macia) foram lavados em água corrente e secos em temperatura ambiente. Após a higienização, a porção comestível do fruto (polpa + casca) foi separada manualmente das sementes, homogeneizada em processador de alimentos e acondicionada em sacos plásticos. Em seguida, a polpa foi branqueada sob imersão em água a $70 \pm 1^{\circ} \mathrm{C}$, por dois minutos, e congelada a $-18 \pm 1^{\circ} \mathrm{C}$.

Foram elaboradas quatro formulações de néctar utilizando-se diferentes concentrações de polpa de cagaita, sacarose e água mineral (Tabela 1). Calculou-se a quantidade de sacarose adicionada a cada formulação de modo a se obter produtos com relação SS/AT na faixa de 18 a 20. Em razão do pH abaixo de 4,0 (CARDOSO et al., 2011) não foi necessária a adição de ácido cítrico para sua correção. 
TABELA 1 - COMPOSIÇÃO DAS FORMULAÇÕES DE NÉCTAR DE CAGAITA

\begin{tabular}{lcccc}
\hline \multicolumn{1}{c}{ Ingredientes } & F20 & F30 & F40 & F50 \\
\hline Polpa (\%) & 20 & 30 & 40 & 50 \\
Água Mineral $(\%)$ & 80 & 70 & 60 & 50 \\
Açúcar $(\mathrm{g} / 100 \mathrm{~mL})$ & 3,3 & 4,0 & 6,7 & 8,0 \\
\hline
\end{tabular}

F20 = formulação contendo $20 \%$ de polpa; F30 = formulação contendo $30 \%$ de polpa; $F 40=$ formulação contendo $40 \%$ de polpa; F50 = formulação contendo $50 \%$ de polpa.

Para obtenção das quatro formulações de néctar adicionou-se água à polpa de cagaita e homogeneizou-se a mistura em processador doméstico de alimentos. Passou-se a mistura em peneira plástica (malha de aproximadamente $1 \mathrm{~mm}$ ), adicionou-se a sacarose e a mistura foi novamente homogeneizada. Após o preparo, o néctar foi acondicionado em garrafas de vidro e pasteurizado a $65 \pm 1{ }^{\circ} \mathrm{C}$ por $30 \mathrm{~min}$ (PALTRINIERI e FIGUEROLA, 1997).

\subsection{ANÁLISES MICROBIOLÓGICAS}

A legislação brasileira (BRASIL, 2001) que estabelece critérios e padrões microbiológicos para alimentos destinados ao consumo humano recomenda o monitoramento de coliformes totais e Salmonella spp. em néctar de frutas. Assim, a presença desses micro-organismos foi avaliada nas quatro formulações utilizando-se a metodologia proposta por Silva, Junqueira e Silveira (2001). Embora a legislação não recomende a contagem de coliformes termotolerantes, bolores e leveduras, esses micro-organismos também foram analisados segundo as metodologias propostas por Silva, Junqueira e Silveira (2001) e da American Public Health Association (APHA, 2001), respectivamente.

Para as análises de coliformes, bolores e leveduras, $25 \mathrm{~mL}$ de cada formulação de néctar foram homogeneizados em $225 \mathrm{~mL}$ de água peptonada. Posteriormente, diluiu-se o extrato obtido na ordem de $10^{-1} ; 10^{-2}$ e $10^{-3}$. Os coliformes (totais e termotolerantes) foram determinados utilizandose a técnica do Número Mais Provável (NMP), sendo inoculado $1 \mathrm{~mL}$ de cada diluição em três tubos contendo Caldo LST (meio presuntivo) e tubos de Durhan, os quais foram incubados a $35^{\circ} \mathrm{C}$ por 48 horas. Para a identificação de bolores e leveduras, $0,1 \mathrm{~mL}$ de cada diluição foi colocado em placas com Ágar PDA acidificado com ácido tartárico $(10 \%)$ e essas incubadas a $25^{\circ} \mathrm{C}$ durante 5 dias.

Para a análise de Salmonella spp., $25 \mathrm{~mL}$ de cada formulação de néctar foram homogeneizados com $225 \mathrm{~mL}$ de Caldo Lactosado e incubados a $35^{\circ} \mathrm{C}$ por 24 horas. Em seguida, $1 \mathrm{~mL}$ desse cultivo foi transferido para $10 \mathrm{~mL}$ de Caldo Selenito-Cistina e $0,1 \mathrm{~mL}$ para $10 \mathrm{~mL}$ de Caldo Rappaport, sendo o primeiro incubado a $35^{\circ} \mathrm{C}$ durante $24 \mathrm{~h}$ e o segundo a $42^{\circ} \mathrm{C}$ por 24 horas em banho maria. Semeou-se uma alçada desses cultivos em placas com Ágar SS e BG, mantendoos a $35^{\circ} \mathrm{C}$ por 24 horas para o isolamento de colônias.

\subsection{ANÁLISE SENSORIAL}

As quatro formulações de néctar foram avaliadas quanto à aceitação da cor, sabor e impressão global por 105 julgadores não treinados, recrutados em supermercado da cidade de Viçosa. Participaram da pesquisa somente os indivíduos que concordaram e assinaram o Termo de Consentimento Livre e Esclarecido.

As amostras foram servidas em temperatura de $5 \pm 1{ }^{\circ} \mathrm{C}$, de forma monádica, em copos plásticos de $50 \mathrm{~mL}$ codificados com algarismos de três dígitos aleatórios. Água filtrada foi fornecida 
para enxágue da boca entre as avaliações. Para avaliação dos parâmetros, utilizou-se escala hedônica estruturada de 9 pontos, sendo atribuído o escore 9 para "gostei extremamente" e o escore 1 para "desgostei extremamente" (STONE e SIDEL, 1993).

\subsection{ANÁLISES QUÍMICAS}

As análises químicas, realizadas na formulação de néctar mais aceita pelos julgadores, ocorreram imediatamente após o preparo do produto.

Foram determinados os teores de acidez titulável (AT), sólidos solúveis (SS) e pH de acordo com as Normas analíticas do Instituto Adolfo Lutz (2005). Umidade, lipídios, proteínas, fibra alimentar total e cinzas totais foram analisados, em amostras liofilizadas por 72 horas, utilizando-se as metodologias da Association of Official Analytical Chemists (AOAC, 1998).

Os carboidratos das amostras foram calculados por diferença usando-se a equação: 100 - \% de umidade - \% de lipídios - \% de proteínas - \% de fibra alimentar total - \% de cinzas. Estimou-se o valor energético total considerando os valores de conversão para carboidratos (4 Kcal. $\left.\mathrm{g}^{-1}\right)$, proteínas $\left(4 \mathrm{Kcal} . \mathrm{g}^{-1}\right)$ e lipídios $\left(9 \mathrm{Kcal} \mathrm{g}^{-1}\right)$ (BRASIL, 2003a).

Foram investigadas a ocorrência e o conteúdo de carotenoides ( $\alpha$-caroteno, $\beta$-caroteno, $\beta$-criptoxantina e licopeno) e vitamina $C$ (na forma de ácido ascórbico - AA). Durante as etapas de extração e análise desses compostos, as amostras e os extratos foram mantidos sob proteção da luz solar e artificial (uso de vidraria âmbar, papel alumínio e cortinas do tipo blackout) e sob proteção do oxigênio (frascos hermeticamente fechados contendo gás nitrogênio no seu interior).

A extração dos carotenoides foi realizada de acordo com Rodriguez-Amaya (1999), com modificações. Cerca de $15 \mathrm{~g}$ do néctar foram homogeneizados em $30 \mathrm{~mL}$ de acetona resfriada por aproximadamente 5 minutos, usando-se microtriturador. A suspensão foi filtrada a vácuo em funil de büchner utilizando-se papel de filtro.

O filtrado foi transferido, em três frações, para funil de separação contendo $25 \mathrm{~mL}$ de éter de petróleo, visando à transferência dos pigmentos da acetona para o éter. Cada fração foi lavada três vezes com água destilada para retirar toda a acetona. Acrescentou-se sulfato de sódio anidro ao extrato para retirar qualquer resíduo de água que, porventura, tivesse restado e que pudesse prejudicar a evaporação do material.

As análises de carotenoides seguiram as condições cromatográficas desenvolvidas por Pinheiro-Sant'Ana et al. (1998), as quais incluíam: sistema CLAE; DAD; coluna RP-18 Phenomenex Gemini, 250 x 4,6 mm, 5 um, munida de coluna de guarda Phenomenex ODS (C18), $4 \mathrm{~mm} \times 3 \mathrm{~mm}$; fase móvel composta de metanol: acetato de etila: acetonitrila (70:20:10, v/v/v); fluxo da fase móvel de $1,7 \mathrm{~mL} /$ minuto; tempo de corrida de, aproximadamente, 12 minutos. Os cromatogramas foram obtidos em comprimento de onda de $450 \mathrm{~nm}$.

Calculou-se o valor de vitamina A conforme as recomendações do Institute of Medicine (2001) em que 1 Equivalente de Atividade de Retinol (RAE) corresponde a $1 \mu \mathrm{g}$ de retinol; $12 \mu \mathrm{g}$ de $\beta$-caroteno; $24 \mu \mathrm{g}$ de outros carotenoides pró-vitamínicos.

Para extração e análise de AA foram utilizadas as condições otimizadas por Campos et al. (2009), com modificações. O AA de $10 \mathrm{~g}$ do néctar foi extraído em $13 \mathrm{~mL}$ de solução extratora (ácido metafosfórico 3\%, ácido acético $8 \%$, ácido sulfúrico 0,3 N e EDTA $1 \mathrm{mM}$ ) usando-se microtriturador. A suspensão obtida foi centrifugada a $4000 \mathrm{rpm}$ (1789 g) por 10 minutos, filtrada a vácuo em funil de büchner e transferida para balão volumétrico de $25 \mathrm{~mL}$, sendo seu volume completado com água ultrapura. Posteriormente, o extrato foi centrifugado a $14000 \mathrm{rpm}(21.913 \mathrm{~g})$ durante 5 minutos e o sobrenadante acondicionado sob refrigeração $\left(5 \pm 1^{\circ} \mathrm{C}\right)$ até o momento da análise por CLAE, que ocorreu no máximo 30 minutos após a extração.

As condições cromatográficas utilizadas para análise de AA foram: coluna cromatográfica RP-18 Lichrospher 100, $250 \times 4 \mathrm{~mm}, 5 \mu \mathrm{m}$; sistema CLAE; DAD; fase móvel composta de água ultrapura contendo $1 \mathrm{mM}$ de fosfato monobásico de sódio, $1 \mathrm{mM}$ de EDTA e pH ajustado para 3,0 
com ácido fosfórico; fluxo da fase móvel de 1,0 mL/minuto; e tempo de corrida de 5 minutos. Os cromatogramas foram obtidos em comprimento de onda de $245 \mathrm{~nm}$ (CAMPOS et al., 2009).

A identificação de carotenoides e AA ocorreu mediante comparação dos tempos de retenção obtidos para os padrões e para as amostras analisadas sob as mesmas condições e comparação dos espectros de absorção do padrão e dos picos de interesse nas amostras, utilizando-se o DAD.

Para quantificação dos compostos encontrados no néctar de cagaita foram utilizadas curvas analíticas obtidas a partir da injeção, em duplicata, de seis concentrações crescentes de soluções dos padrões na faixa de 0,004 a 1,433 $\mu \mathrm{g}$ para $\beta$-caroteno; 0,004 a 1,433 $\mu \mathrm{g}$ para $\beta$-criptoxantina e 0,0589 a $5,8800 \mu \mathrm{g}$ para AA. Efetuou-se a quantificação dos compostos no néctar a partir das equações de regressão obtidas para $\beta$-caroteno $\left(y=1389460,94 x+24320,87 ; R^{2}=\right.$ $0,996)$, $\beta$-criptoxantina $\left(y=1661804,24 x+18345,98 ; R^{2}=0,998\right)$ e $A A(y=3277607,19 x-66204,16$; $\left.R^{2}=0,998\right)$.

\subsection{ESTABILIDADE DO PRODUTO}

Para o estudo da estabilidade do produto, 2 lotes da formulação de néctar mais aceita pelos julgadores foram submetidos a condições que simulam o armazenamento comercial em freezer $\left(-18^{\circ} \mathrm{C}\right)$ (Lote 1$)$ e doméstico em geladeira $\left(5^{\circ} \mathrm{C}\right)$ (Lote 2$)$.

Após o preparo, alíquotas do Lote $1(30 \mathrm{~mL})$ foram acondicionadas em sacos plásticos e armazenadas em freezer a $-18^{\circ} \mathrm{C} \pm 1^{\circ} \mathrm{C}$ durante 90 dias. Posteriormente, foram realizadas análises de AT, SS e pH (0; 16; 30; 60 e 90 dias de armazenamento), carotenoides e AA ( 3,6 e 24 horas e 3 , $9,16,23,30,45,60$ e 90 dias de armazenamento).

$\mathrm{O}$ Lote 2 foi acondicionado em garrafas de vidro e armazenado em geladeira a $5^{\circ} \mathrm{C} \pm 1^{\circ} \mathrm{C}$ durante 72 horas. Nesse lote foram avaliados carotenoides e AA $(3,6,9,12,24$, 48 e 72 horas de armazenamento). Considerando que, devido ao curto período de armazenamento, as alterações em SS, pH e AT não seriam significativas, esses parâmetros não foram analisados nesse lote.

Para verificar possíveis perdas decorrentes do processamento do néctar comparou-se o conteúdo de carotenoides e AA logo após o processamento do néctar (Lote 1) com o conteúdo da polpa in natura utilizada para elaboração desse lote (controle).

\subsection{DELINEAMENTO EXPERIMENTAL E ANÁLISE ESTATÍSTICA}

Adotou-se delineamento inteiramente casualizado para as análises microbiológicas e químicas, com três repetições. Para a análise sensorial empregou-se delineamento em blocos casualizados, sendo os blocos representados pelos julgadores.

Os dados da análise sensorial foram submetidos à análise de variância (ANOVA), ao teste de Tukey ao nível de $5 \%$ de significância e à técnica de Mapa de Preferência Interno, baseada no modelo de Análise de Componente Principal (CARNEIRO, 2001). Os dados de estabilidade de carotenoides e AA foram submetidos à ANOVA. Todas as análises estatísticas foram conduzidas utilizando-se o software SAS, versão 9.1 (2002-2003), licenciado para a UFV.

\section{RESULTADOS E DISCUSSÃO}

\subsection{CARACTERIZAÇÃO MICROBIOLÓGICA}

Verificou-se a ausência de coliformes totais e de Salmonella spp. nas quatro formulações de néctar de cagaita, o que está de acordo com o recomendando pela legislação brasileira que estabelece padrões sanitários para alimentos destinados ao consumo humano (BRASIL, 2001). Além disso, não foi constatada a presença de coliformes termotolerantes, bolores e leveduras em todas as formulações analisadas. 
A ausência dos micro-organismos investigados indica que as formulações de néctar não oferecem risco de toxinfecção ao consumidor. A inocuidade dos produtos resultou das boas práticas adotadas durante o seu processamento, eficiência do tratamento térmico (pasteurização) e das características químicas dos produtos, especialmente, o pH ácido.

$\mathrm{O}$ uso combinado de pasteurização e controle do pH constitui alternativa de conservação para produtos alimentícios em que a esterilização comercial pelo calor é inviável. O emprego de calor mediante pasteurização elimina os micro-organismos patogênicos e parte dos micro-organismos alteradores (ANDRADE, 2008), enquanto que o pH ácido (inferior a 4,5) inibe o crescimento de bactérias, fungos e leveduras sensíveis ao meio (SILVA et al., 2005). Destaca-se que no produto desenvolvido, o tratamento térmico representou o único ponto crítico de controle da produção, uma vez que não houve outro tratamento que eliminasse os micro-organismos.

\subsection{CARACTERIZAÇÃO SENSORIAL}

As amostras de néctar foram avaliadas por 105 consumidores (79 mulheres e 26 homens) com idade entre 15 a 70 anos.

As formulações F20 e F30 não diferiram entre si $(p>0,05)$ em todos os atributos sensoriais avaliados e apresentaram aceitação significativamente menor que as formulações F40 e F50 $(p<0,05)$, as quais também não diferiram entre si $(p>0,05)$ (Tabela 2). As formulações F40 e F50 apresentaram escores de aceitação variando entre os termos hedônicos "gostei moderadamente" e "gostei muito", indicando que foram bem aceitas.

\section{TABELA 2 - CARACTERIZAÇÃO SENSORIAL DAS QUATRO FORMULAÇÕES DE NÉCTAR DE CAGAITA}

\begin{tabular}{lcccc}
\hline Atributo & F20 & F30 & F40 & F50 \\
\hline Cor & $6,27 \pm 2,09^{\mathrm{b}}$ & $6,58 \pm 1,95^{\mathrm{b}}$ & $7,57 \pm 1,38^{\mathrm{a}}$ & $7,78 \pm 1,29^{\mathrm{a}}$ \\
Sabor & $5,22 \pm 2,32^{\mathrm{b}}$ & $5,51 \pm 2,20^{\mathrm{b}}$ & $7,33 \pm 1,47^{\mathrm{a}}$ & $7,56 \pm 1,64^{\mathrm{a}}$ \\
Impressão Global & $5,37 \pm 3,23^{\mathrm{b}}$ & $5,71 \pm 2,20^{\mathrm{b}}$ & $7,32 \pm 1,48^{\mathrm{a}}$ & $7,51 \pm 1,56^{\mathrm{a}}$ \\
\hline
\end{tabular}

Dados apresentados em média \pm desvio padrão; F20 = formulação com $20 \%$ de polpa; $F 30$ = formulação com $30 \%$ de polpa; $\mathrm{F} 40$ = formulação com $40 \%$ de polpa; $\mathrm{F} 50$ = formulação com $50 \%$ de polpa. Médias seguidas pela mesma letra na linha não diferem entre si pelo teste de Tukey ao nível de $5 \%$ de probabilidade.

Boa aceitação de néctar elaborado a partir de frutos exóticos foi observada por Souza Filho et al. (2002) que desenvolveram e avaliaram néctar de mangaba.

A maior aceitação das formulações F40 e F50 deve-se as maiores concentrações de polpa ( $40 \%$ e $50 \%$, respectivamente) e, consequentemente, de SS, ácidos orgânicos e outros compostos que podem afetar a cor, o sabor e a viscosidade do produto. O teor de SS está relacionado com o índice dos açúcares totais, assim quantidades elevadas de SS proporcionam melhor sabor ao produto (SOUZA, 2007).

A Figura 1 mostra a projeção dos resultados da aceitação da impressão global das amostras de néctar, obtidos por meio do Mapa de Preferência Interno (cada ponto representa as correlações entre os dados de aceitação de um consumidor e os dois primeiros componentes principais). Os consumidores correlacionados com pelo menos um dos componentes consideraram diferença na aceitação das amostras, e os mais próximos do centro do gráfico não se correlacionaram com nenhum dos dois componentes principais e contribuíram pouco para a discriminação das amostras (consumidores que consideraram as amostras com aceitação semelhante). $O$ primeiro componente principal (PCP) explicou $70,4 \%$ da variação e o segundo 19,5\%, totalizando $89,9 \%$ da variância 
entre as amostras, sendo suficiente para discriminá-las quanto à aceitação.

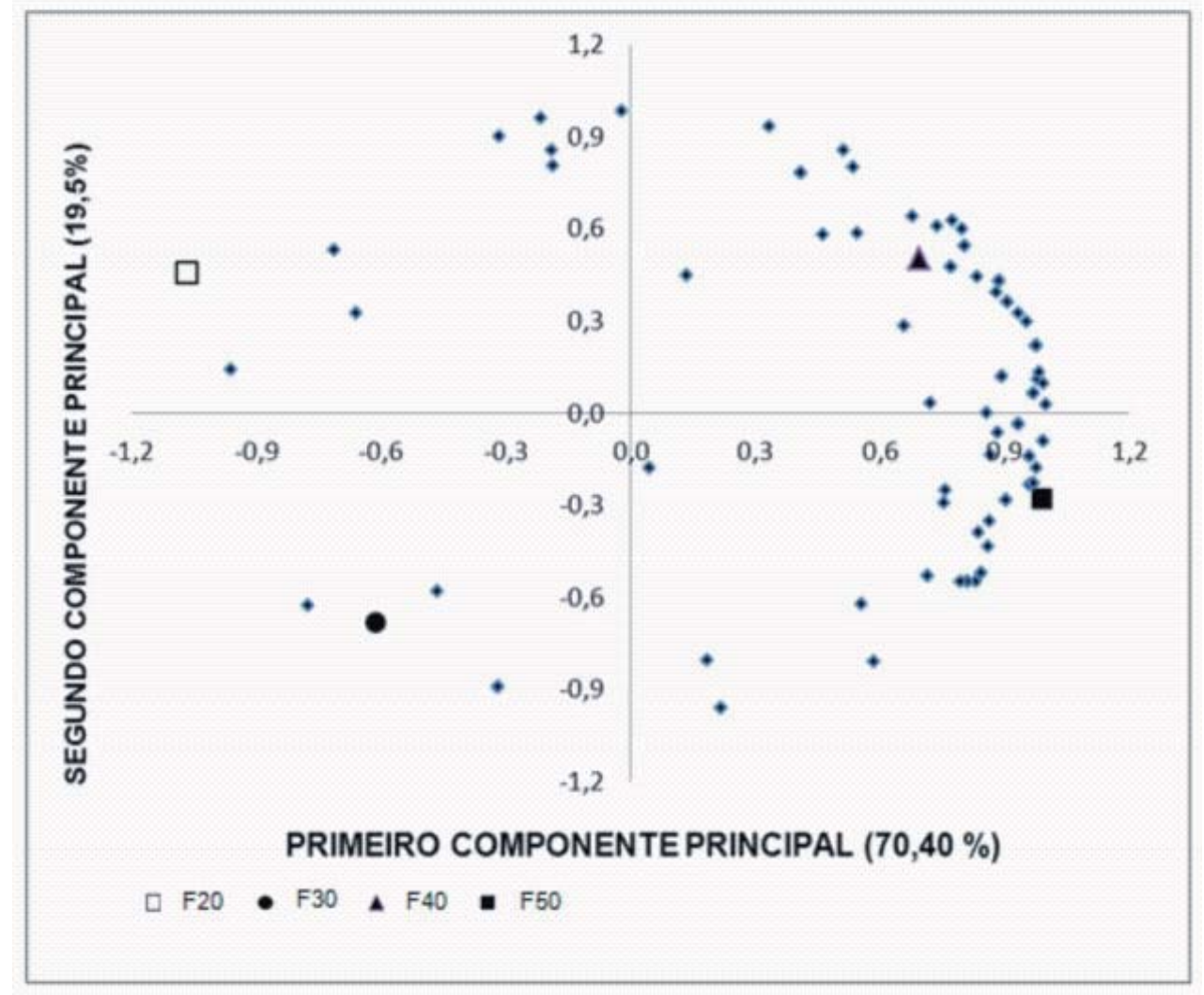

\section{FIGURA 1 - CORRELAÇÕES ENTRE OS DADOS DE ACEITAÇÃO DE CADA CONSUMIDOR E OS DOIS PRIMEIROS COMPONENTES PRINCIPAIS E DISPERSÃO DE FORMULAÇÕES DE NÉCTAR DE CAGAITA EM RELAÇÃO À ACEITAÇÃO}

F20 = formulação com $20 \%$ de polpa; $F 30$ = formulação com $30 \%$ de polpa; $F 40$ = formulação com $40 \%$ de polpa; $\mathrm{F} 50$ = formulação com $50 \%$ de polpa .

A separação espacial das formulações de néctar de cagaita confirmou a ANOVA que demonstrou diferença entre elas, havendo a formação de dois grupos distintos de acordo com a aceitação em relação à impressão global das amostras. Verificou-se que a maior parte dos consumidores correlacionou-se positivamente com o primeiro componente principal, indicando a atribuição de notas mais elevadas para as formulações F40 e F50.

Uma vez que as formulações F40 e F50 apresentaram a mesma aceitação, selecionouse a F50 para a realização das análises químicas e para o estudo de estabilidade devido maior quantidade de polpa.

\subsection{CARACTERIZAÇÃO QUÍMICA}

O néctar de cagaita (F50) apresentou teor de SS de 11,43 ${ }^{\circ} \mathrm{Brix}, \mathrm{pH}$ igual a 3,59 e AT de $0,59 \mathrm{~g}$ de ácido cítrico $100 \mathrm{~g}^{-1}$. A relação SS/AT da formulação F50 $(19,37)$ variou na faixa de $18 \mathrm{a}$ 20, recomendada por Paltrinieri e Figuerola (1997). A relação SS/AT está diretamente relacionada com a qualidade do produto em termos de sabor, evidenciando o equilíbrio entre os açúcares e a acidez que torna seu sabor mais agradável ao paladar (CHITARRA e CHITARRA, 2005).

O néctar de cagaita apresentou (em $100 \mathrm{~g}$ ) 85,75 g de umidade; 0,29 g de proteínas; 
0,27 $\mathrm{g}$ de lipídios; $12,93 \mathrm{~g}$ de carboidratos; $0,68 \mathrm{~g}$ de fibra alimentar total; $0,08 \mathrm{~g}$ de cinzas e $55,31 \mathrm{kcal}$. Os teores de carboidratos, proteínas, lipídios, fibra alimentar, cinzas e o valor energético encontraram-se de acordo com as faixas observadas em néctares industrializados de pera, pêssego e damasco (USDA, 2009), demonstrando que a composição desses produtos não difere muito mesmo quando resultam de diferentes frutas.

Observou-se reduzido conteúdo de carotenoides $\left(0,25 \mathrm{mg} 100 \mathrm{~g}^{-1}\right)$, dos quais $44 \%$ corresponderam a $\beta$-caroteno e $56 \%$ a $\beta$-criptoxantina. Esse resultado mostrou-se inferior ao

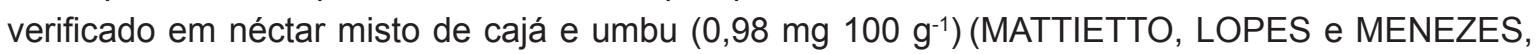
2007) e néctar de frutas tropicais (acerola, caju e manga) com extratos de plantas (1,2 mg $100 \mathrm{~g}^{-1}$ ) (SOUSA et al., 2010). Em razão do baixo conteúdo de carotenoides pró-vitamínicos $\mathrm{A}$, o néctar apresentou reduzido valor de vitamina A (14,69 RAE $\left.100 \mathrm{~g}^{-1}\right)$.

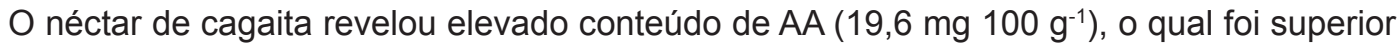

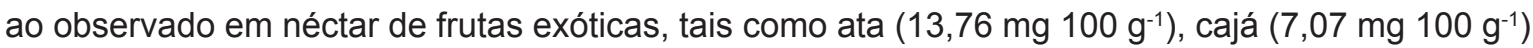
e sapoti (5,57 mg $\left.100 \mathrm{~g}^{-1}\right)$ (SOUZA FILHO et al., 2002).

Os alimentos podem ser classificados como "fontes" de determinado nutriente quando suprem de 5 a $10 \%$ da Dietary Reference Intake (DRI); como "boas fontes" quando suprem de 10 a $20 \%$ da DRI, e como "excelentes fontes" quando atendem mais de $20 \%$ da DRI (PHILIPPI, 2008). Considerando a recomendação de vitamina C para crianças, com idade entre 4 e 8 anos, homens adultos e gestantes com idade entre 19 e 30 anos (IOM, 2000), o néctar de cagaita ( $200 \mathrm{~mL}$ ) (BRASIL, 2003b) mostrou-se excelente fonte de vitamina C, suprindo respectivamente $157 \%, 44 \%$ e $46 \%$ das recomendações para cada um desses grupos.

\subsection{ESTABILIDADE DO PRODUTO}

Não houve alteração significativa $(p>0,05)$ quanto ao $\mathrm{pH}, \mathrm{SS}$, AT e relação SS/AT ao longo do período de armazenamento do néctar estudado (Tabela 3). A manutenção dos teores de SS também foi observada em néctar de amora-preta armazenado a $-18^{\circ} \mathrm{C} \pm 1^{\circ} \mathrm{C}$, por 90 dias (ARAÚJO et al., 2009). A ausência de alterações significativas quanto ao $\mathrm{pH}$ e AT indica que os ácidos orgânicos presentes no néctar de cagaita não sofreram oxidação ao longo do armazenamento (LIMA et al., 2008). As reações oxidativas podem causar escurecimento, alteração da cor, sabor, aroma, textura e valor nutricional de alimentos, como frutas, hortaliças e produtos processados (MATTIETTO, LOPES e MENEZES, 2007).

\section{TABELA 3 - CARACTERÍSTICAS QUÍMICAS DO NÉCTAR DE CAGAITA CONGELADO $\left(-18 \pm 1^{\circ} \mathrm{C}\right)$ DURANTE O PERÍODO DE ARMAZENAMENTO}

\begin{tabular}{ccccc}
$\begin{array}{c}\text { Tempo de } \\
\begin{array}{c}\text { Armazenamento } \\
\text { (dias) }\end{array}\end{array}$ & $\mathbf{p H}$ & $\begin{array}{c}\text { Sólidos Solúveis } \\
\text { ('Brix) }\end{array}$ & $\begin{array}{c}\text { Acidez Titulável } \\
\text { (\% ácido cítrico) }\end{array}$ & Relação SS/AT \\
\hline 0 & $3,59 \pm 0,01$ & $11,43 \pm 1,10$ & $0,59 \pm 0,08$ & $19,37 \pm 0,79$ \\
16 & $3,57 \pm 0,00$ & $10,67 \pm 0,32$ & $0,54 \pm 0,01$ & $19,75 \pm 0,75$ \\
30 & $3,57 \pm 0,00$ & $10,93 \pm 0,11$ & $0,55 \pm 0,01$ & $19,87 \pm 0,59$ \\
60 & $3,57 \pm 0,03$ & $11,80 \pm 1,41$ & $0,58 \pm 0,05$ & $20,19 \pm 0,74$ \\
90 & $3,54 \pm 0,07$ & $11,47 \pm 0,91$ & $0,56 \pm 0,04$ & $20,43 \pm 0,33$ \\
\hline
\end{tabular}

Média de 3 repetições; Dados apresentados em média \pm desvio padrão; Médias na coluna, para cada componente, não diferem entre si ao nível de $5 \%$ de probabilidade pela análise de variância. 
O conteúdo de carotenoides e AA na formulação F50 logo após o preparo (Tabela 4) correspondeu à metade do conteúdo desses nutrientes na polpa in natura $\left(0,41 \mathrm{mg} 100 \mathrm{~g}^{-1} \mathrm{e}\right.$ $45,5 \mathrm{mg} 100 \mathrm{~g}^{-1}$, respectivamente), indicando que a redução se deve exclusivamente à diluição ocorrida durante o processamento. Apesar de se saber que o processamento dos alimentos pode alterar o conteúdo de nutrientes, nem todos resultam em perdas (MAIA et al., 2007).

\section{TABELA 4 - CONTEÚDO DE CAROTENOIDES E ÁCIDO ASCÓRBICO EM NÉCTAR DE CAGAITA CONGELADO $\left(-18 \pm 1^{\circ} \mathrm{C}\right)$ AO LONGO DO PERÍODO DE ARMAZENAMENTO}

\begin{tabular}{|c|c|c|c|}
\hline $\begin{array}{c}\text { Tempo de } \\
\text { Armazenamento }\end{array}$ & $\begin{array}{l}\boldsymbol{\beta} \text {-Caroteno } \\
\left(\mathrm{mg} 100 \mathrm{~g}^{-1}\right)\end{array}$ & $\begin{array}{c}\boldsymbol{\beta} \text {-Criptoxantina } \\
\left(\mathrm{mg} 100 \mathrm{~g}^{-1}\right)\end{array}$ & $\begin{array}{c}\text { Ácido Ascórbico } \\
\left(\mathrm{mg} 100 \mathrm{~g}^{-1}\right)\end{array}$ \\
\hline Após o preparo & $0,11 \pm 0,01$ & $0,14 \pm 0,01$ & $19,60 \pm 0,88$ \\
\hline 3 horas & $0,09 \pm 0,02$ & $0,14 \pm 0,02$ & $20,69 \pm 0,73$ \\
\hline 6 horas & $0,09 \pm 0,01$ & $0,13 \pm 0,01$ & $20,71 \pm 0,62$ \\
\hline 24 horas & $0,08 \pm 0,00$ & $0,13 \pm 0,00$ & $22,30 \pm 0,94$ \\
\hline 3 dias & $0,10 \pm 0,05$ & $0,13 \pm 0,05$ & $21,18 \pm 0,59$ \\
\hline 9 dias & $0,11 \pm 0,03$ & $0,11 \pm 0,00$ & $21,13 \pm 0,39$ \\
\hline 16 dias & $0,09 \pm 0,04$ & $0,12 \pm 0,01$ & $21,78 \pm 0,39$ \\
\hline 23 dias & $0,07 \pm 0,01$ & $0,11 \pm 0,02$ & $21,51 \pm 2,56$ \\
\hline 30 dias & $0,11 \pm 0,07$ & $0,13 \pm 0,03$ & $22,36 \pm 1,91$ \\
\hline 45 dias & $0,07 \pm 0,01$ & $0,11 \pm 0,01$ & $21,48 \pm 0,34$ \\
\hline 60 dias & $0,08 \pm 0,03$ & $0,14 \pm 0,02$ & $21,60 \pm 1,55$ \\
\hline 90 dias & $0,09 \pm 0,03$ & $0,13 \pm 0,01$ & $22,79 \pm 0,43$ \\
\hline
\end{tabular}

Média de 3 repetições; Dados apresentados em média \pm desvio padrão; Médias na coluna, para cada componente, não diferem entre si ao nível de $5 \%$ de probabilidade pela análise de variância.

Não houve diferença significativa $(p>0,05)$ nos conteúdos de carotenoides e AA do néctar congelado (Tabela 4) e do refrigerado (Tabela 5) durante o armazenamento, o que sugere excelente estabilidade desses compostos frente às condições de armazenamento empregadas.

Estudos sobre a estabilidade de vitamina $\mathrm{C}$ e carotenoides em néctar ou suco de frutas, utilizando as mesmas condições do presente trabalho são escassos. Silva et al. (2007) avaliando suco de laranja refrigerado por 7 dias ou congelado durante 180 dias não observaram diferenças no seu conteúdo de vitamina C. Freitas et al. (2006) não verificaram variações significativas do conteúdo de carotenoides em suco tropical de acerola industrializado durante armazenamento por 350 dias sob temperatura ambiente.

A estabilidade do AA observada no néctar de cagaita analisado deveu-se ao $\mathrm{pH}$ ácido do produto e ao fato de ter sido mantido sob congelamento ou refrigeração durante o armazenamento. 
A vitamina $C$ é mais estável em meio ácido e em baixas temperaturas, sendo o controle da temperatura importante instrumento para prolongar a vida-de-prateleira e manter a qualidade de produtos alimentícios (SEBASTIANY et al., 2008). Comportamento similar foi observado para os carotenoides, podendo sua estabilidade ser aumentada com a redução da temperatura (CAMPOS et al., 2006). Outro fator que possivelmente contribuiu para a estabilidade dos carotenoides e AA no néctar analisado foi o branqueamento. A presença de enzimas oxidativas, como as oxidases e peroxidases, reduzem os teores desses compostos. No entanto, o branqueamento da polpa utilizado para a elaboração do néctar inativa essas enzimas, aumentando a estabilidade na estocagem de alimentos cuja atividade enzimática continua mesmo depois do processamento (NASCIMENTO, 2006; ARAÚJO et al., 2009).

\section{TABELA 5 - CONTEÚDO DE CAROTENOIDES E ÁCIDO ASCÓRBICO EM NÉCTAR DE CAGAITA REFRIGERADO $\left(5 \pm 1^{\circ} \mathrm{C}\right)$ AO LONGO DO PERÍODO DE ARMAZENAMENTO}

\begin{tabular}{|c|c|c|c|}
\hline $\begin{array}{c}\text { Tempo de } \\
\text { Armazenamento }\end{array}$ & $\begin{array}{l}\boldsymbol{\beta} \text {-Caroteno } \\
\left(\mathrm{mg} 100 \mathrm{~g}^{-1}\right)\end{array}$ & 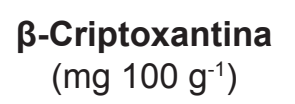 & 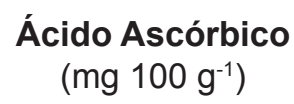 \\
\hline Após o preparo & $0,27 \pm 0,02$ & $0,14 \pm 0,02$ & $14,15 \pm 2,71$ \\
\hline 3 horas & $0,27 \pm 0,03$ & $0,15 \pm 0,03$ & $13,27 \pm 1,99$ \\
\hline 6 horas & $0,27 \pm 0,03$ & $0,14 \pm 0,01$ & $13,39 \pm 2,54$ \\
\hline 9 horas & $0,21 \pm 0,05$ & $0,12 \pm 0,02$ & $13,51 \pm 2,69$ \\
\hline 12 horas & $0,22 \pm 0,02$ & $0,14 \pm 0,02$ & $13,57 \pm 2,47$ \\
\hline 24 horas & $0,25 \pm 0,09$ & $0,15 \pm 0,06$ & $13,87 \pm 2,48$ \\
\hline 48 horas & $0,27 \pm 0,06$ & $0,16 \pm 0,05$ & $13,42 \pm 1,87$ \\
\hline 72 horas & $0,22 \pm 0,03$ & $0,15 \pm 0,04$ & $14,60 \pm 1,75$ \\
\hline
\end{tabular}

Média de 3 repetições; Dados apresentados em média \pm desvio padrão; Médias na coluna, para cada componente, não diferem entre si ao nível de $5 \%$ de probabilidade pela análise de variância.

\section{CONCLUSÃO}

As formulações de néctar de cagaita desenvolvidas atenderam aos padrões químicos e microbiológicos estabelecidos pela legislação brasileira.

Para todos os atributos sensoriais avaliados, as formulações contendo $40 \%$ e $50 \%$ de polpa de cagaita foram as mais aceitas pelos consumidores.

O néctar de cagaita, contendo $50 \%$ de polpa, mostrou-se excelente fonte de vitamina C para crianças, gestantes e adultos. Observou-se reduzido conteúdo de proteínas, lipídios, fibra alimentar total, carotenoides e valor de vitamina $\mathrm{A}$.

Constatou-se excelente estabilidade do produto, não havendo alteração significativa das suas características químicas e nutricionais ao longo do armazenamento sob refrigeração $\left(5^{\circ} \mathrm{C} / 72\right.$ horas) e congelamento $\left(-18^{\circ} \mathrm{C} / 90\right.$ dias $)$.

O néctar de cagaita apresentou potencial tecnológico, podendo ser produzido, consumido e comercializado por populações nativas do Cerrado, contribuindo para o aporte nutricional e geração de renda para essas populações. 


\section{ABSTRACT \\ CAGAITA NECTAR (Eugenia dysenterica DC.): DEVELOPMENT, MICROBIOLOGICAL, SENSORY AND CHEMICAL CHARACTERIZATION, AND STABILITY STUDY}

This study aimed to develop cagaita nectar (Eugenia dysenterica DC.) and characterize them regarding microbiological, sensory, and chemical parameters, and product stability during the storage. Four formulations of nectar containing $20,30,40$ and $50 \%$ of pulp were developed and evaluated microbiologically (total and thermotolerant coliforms, molds, yeasts and Salmonella spp) and sensory (acceptance testing). The most accepted formulation was investigated for the content of soluble solids (SS), $\mathrm{pH}$, titratable acidity (TA), relation SS/TA, moisture, protein, lipids, carbohydrates, total dietary fiber (TDF), ash, carotenoids and ascorbic acid (AA), and stability while stored under freezing $\left(-18^{\circ} \mathrm{C} / 90\right.$ days $)$ and refrigeration $\left(5^{\circ} \mathrm{C} / 72\right.$ hours). It was observed an absence of microorganisms in the four formulations examined. The formulations with 40 and $50 \%$ of pulp presented greater acceptance of color, flavor and overall impression. The nectar containing $50 \%$ of pulp presented SS of $11.43^{\circ} \mathrm{Brix}, \mathrm{pH} 3.59$ and relation SS/TA of 19.37 . In $100 \mathrm{~g}$ was found TA of $0.59 \mathrm{~g}$ of citric acid, $85.75 \mathrm{~g}$ of moisture, $0.29 \mathrm{~g}$ of protein, $0.27 \mathrm{~g}$ of lipids, $12.93 \mathrm{~g}$ of carbohydrates, $0.68 \mathrm{~g}$ of TDF, $0.08 \mathrm{~g}$ of ash, $55.31 \mathrm{kcal}, 0.25 \mathrm{mg}$ of carotenoids and $19.6 \mathrm{mg}$ of AA. During storage, there were no statistically significant changes in the values of SS, TA, pH, carotenoids and AA. The cagaita nectar attended to the chemical and the microbiological standards established by the Brazilian law, and has reached a good acceptance of consumers, and showed excellent stability during storage.

KEY-WORDS: CAGAITA; Eugenia dysenterica; NECTAR; SENSORY ANALYSIS.

\section{REFERÊNCIAS}

1 ALMEIDA, S.P.; PROENÇA, C.E.B.; SANO, S.M.; RIBEIRO, J.F. Cerrado: espécies vegetais úteis. Planaltina: EMBRAPACPAC, 1998. 464 p.

2 ANDRADE, N. J. Higiene na indústria de alimentos: avaliação e controle da adesão e formação de biofilmes bacterianos. São Paulo: Varela, 2008

3 Association of Official Analytical Chemists (AOAC). Official methods of analysis of the AOAC International. $16^{\text {th }}$ ed. Washington, DC, 1998. $1170 \mathrm{p}$.

4 American Public Health Association (APHA). Compendium of methods for the microbiological examination of foods. Washington, DC, 2001.

5 ARAÚJO, P.F.; RODRIGUES, R.S.; MACHADO, A.R.; SANTOS, V.S.; SILVA, J.A. Influencia do congelamPento sobre as características físico-químicas e o potencial antioxidante de néctar de amora-preta. Boletim do CEPPA, Curitiba, v.27, n.2, p.199-206, 2009.

6 BRASIL. Ministério da Agricultura. Decreto $n^{\circ} 6871$, de 4 de junho de 2009. Dispõe sobre a padronização, a classificação, o registro, a inspeção e a fiscalização da produção e do comércio de bebidas. Diário Oficial [da] República Federativa do Brasil, Brasília, DF, 04 de junho de 2009.

7 BRASIL. Ministério da Saúde. Agência Nacional de Vigilância Sanitária (ANVISA). Resolução RDC n¹2, de 02 de janeiro de 2001. Dispões sobre os princípios gerais para o estabelecimento de critérios e padrões microbiológicos para alimentos. Diário Oficial [da] República Federativa do Brasil, Brasília, DF, 10 de janeiro de 2001.

8 BRASIL. Ministério da Saúde. Agência Nacional de Vigilância Sanitária (ANVISA). Resolução RDC $n^{\circ} 360,23$ de dezembro de 2003. Dispõe sobre regulamento técnico sobre rotulagem nutricional de alimentos embalados. Diário Oficial [da] República Federativa do Brasil, Brasília, DF, 26 de dezembro de 2003a.

9 BRASIL. Ministério da Saúde. Agência Nacional de Vigilância Sanitária (ANVISA). Resolução RDC $n^{\circ} 359,23$ de dezembro de 2003. Aprova o regulamento técnico de porções de alimentos embalados para fins de rotulagem nutricional. Diário Oficial [da] República Federativa do Brasil, Brasília, DF, 26 de dezembro de 2003b.

10 CAMPOS, F.M.; PINHEIRO-SANT'ANA, H.M.; SOUZA, P.M.; STRINGHETA, P.C.; CHAVES, J.B.P. Pró-vitaminas A em hortaliças comercializadas no mercado formal e informal de viçosa (MG), em três estações do ano. Ciência e Tecnologia de Alimentos, Campinas, v.26, n.1, p.33-40, 2006.

11 CAMPOS, F.M.; RIBEIRO, S.M.R.; DELLA LUCIA, C.M.; PINHEIRO-SANT'ANA, H. M. Optimization of methodology to analyze ascorbic and dehydroascorbic acid in vegetables. Química Nova, v.32, n.1, p.87-91, 2009.

12 CARDOSO, L.M.; MARTINO, H.S.D.; MOREIRA, A.V.B.; RIBEIRO, S.M.R.; PINHEIRO-SANT'ANA, H.M. Cagaita (Eugenia dysenterica DC.) of the Cerrado of Minas Gerais, Brazil: physical and chemical characterization, carotenoids and vitamins. Food Research International, v.44, n.7, p.2151-2154, 2011. 
13 CARNEIRO, J.C.S. Processamento industrial de feijão, avaliação sensorial descritiva e mapa de preferência. 2001. 90 f. Dissertação (Mestrado em Ciência e Tecnologia de Alimentos) - Universidade Federal de Viçosa, Viçosa, 2001.

14 CHITARRA, M.I.F.; CHITARRA, A.B. Pós-colheita de frutas e hortaliças: fisiologia e manuseio. Lavras: Editora UFLA, 2005. $785 \mathrm{p}$.

15 FREITAS, C.A.S.; MAIA, G.A.; COSTA, J.M.C.; FIGUEIREDO, R.W.; SOUSA, P.H. M.; FERNANDES, A.G. Estabilidades dos carotenoides, antocianinas e vitamina C presentes em suco tropical de acerola (Malpighia emarginata DC.) adoçado envasado pelos processos hot-fill e asséptico. Ciência e Agrotecnologia, Lavras, v.30, n.5, p.942-949, 2006.

16 INSTITUTO ADOLFO LUTZ. Normas analíticas do Instituto Adolfo Lutz: métodos químicos e físicos para análise de alimentos. São Paulo: Secretaria do Estado de Saúde, 2005. 60 p.

17 INSTITUTE OF MEDICINE. Dietary reference intakes for vitamin C, vitamin E, selenium, and carotenoids. Washington, DC: National Academy Press, 2000. 529 p.

18 INSTITUTE OF MEDICINE. Dietary reference intakes for vitamin A, vitamin K, arsenic, boron, chromium, copper, iodine, iron, manganese, molybdenum, nickel, silicon, vanadium, and zinc. Washington, D.C.: National Academy Press, 2001. 800 p.

19 LIMA; A.S.; MAIA, G.A.; SOUSA, P.H.M.; SILVA, F.V.G.; FIGUEIREDO, E.A.T. Desenvolvimento de bebida mista à base de água de coco e suco de acerola. Ciência e Tecnologia de Alimentos, Campinas, v.28, n.3, p.683-690, 2008.

20 MAIA, G.A.; SOUSA, P.H.M.; SANTOS, G.M.; SILVA, D.S.; FERNANDES, A.G.; PRADO, G.M. Efeito do processamento sobre componentes do suco de acerola. Ciência e Tecnologia de Alimentos, Campinas, v.27, n.1, p.130-134, 2007

21 MATTIETTO, R.A.; LOPES, A.S.; MENEZES, H.C. Estabilidade do néctar misto de cajá e umbu. Ciência e Tecnologia de Alimentos, Campinas, v.27, n.3, p.456-463, 2007.

22 NASCIMENTO, P. Avaliação da retenção de carotenoides da abóbora, mandioca e batata doce. 2006.67 f. Dissertação (Mestrado em Engenharia e Ciência de Alimentos) - Universidade Estadual Paulista, São José do Rio Preto, 2006.

23 PALTRINIERI, G.; FIGUEROLA, F. Procesamiento a pequeña escala de frutas y hortalizas amazônicas nativas y introducidas. Lima: Secretaria Pro-Tempore - Tratado de Cooperacion Amazonica, 1997. 2147 p

24 PHILIPPI, S. T. Pirâmide dos alimentos: fundamentos básicos da nutrição. São Paulo: Manole, 2008. 381p.

25 PINHEIRO-SANT'ANA, H.M.; STRINGHETA, P.C.; BRANDÃO, S.C.C.; AZEREDO, R.M.C. Carotenoid retention and vitamin A value in carrot (Daucus carota L.) prepared by food service. Food Chemistry, v.61, n.1/2, p.145-151, 1998.

26 PROENÇA, C.; OLIVEIRA, R.S.; SILVA, A.P. Flores e frutos do Cerrado. São Paulo: Editora Universidade Brasília, Imprensa Oficial, Brasil, 2000

27 RODRIGUEZ-AMAYA, D.B. Critical review of provitamin A determination in plant foods. Journal of Micronutrient Analysis, v.5, n.1, p.191-225, 1989.

28 RODRIGUEZ-AMAYA, D.B. Latin American food sources of carotenoids. Archivos Latinoamericanos de Nutrición, v.49, n.1, p.74-84, 1999.

29 SAS Institute. Statistical analysis system. Version 9.1. Cary, North Carolina, 2002-2003.

30 SEBASTIANY, E.; MOURA, E.R.; RÊGO, E.R.; VITAL, M.J.S. Perda de vitamina C durante o armazenamento de polpa de acerola congelada. Boletim do CEPPA, Curitiba, v.27, n.2, p.281-288, 2008.

31 SHIMADZU CORPORATION. Multi system software, Class Vp. Version 6.12. Kyoto, Japan, 2000.

32 SILVA, M.R.; CAVALCANTE, L.L.; SANTOS, G.G.; MARTINS, D.M.O. Caracterização química de frutos nativos do cerrado. Ciência Rural, Santa Maria, v.38, n.6, p.1790-1793, 2008.

33 SILVA, N.; JUNQUEIRA, V.C.A.; SILVEIRA, N.F.A. Manual de métodos de análises microbiológicas de alimentos. 2. ed. São Paulo: Livraria Varela, 2001. 229 p.

34 SILVA, P.T.; FIALHO, E.; MIGUEL, M.A.L.; LOPES, M.L.M.; VALENTE-MESQUITA, V.L. Estabilidade química, físicoquímica e microbiológica de suco de laranja cv. "pera" submetido a diferentes condições de estocagem. Boletim do CEPPA, Curitiba, v.25, n.2, p.235-246, 2007.

35 SILVA, R.A.; OLIVEIRA, A.B.; FELIPE, E.M.F.; NERES, F.P.T.J.; MAIA, G.A.; COSTA, J.M.C. Avaliação físico-química e sensorial de néctares de manga de diferentes marcas comercializadas em Fortaleza/CE. Publicatio UEPG Ciências Exatas da Terra, Ciências Agrárias e Engenharias, Ponta Grossa, v.11, n.3, p.21-26, 2005. 
36 SILVA, R.S.M.; CHAVES, L.J.; NAVES, R.V. Caracterização de frutos e árvores de cagaita (Eugenia dysenterica DC.) no sudeste do Estado de Goiás, Brasil. Revista Brasileira de Fruticultura, Jaboticabal, v.23, n.2, p.330-334, 2001.

37 SOUSA, P.H.; RAMOS, A.M.; MAIA, G.A.; BRITO, E.S.; GARRUTI, D.S.; FONSECA, A.V.V. Adição de extratos de Ginkgo biloba e Panax ginseng em néctares mistos de frutas tropicais. Ciência e Tecnologia de Alimentos, Campinas, v.30, n.2, p.463-470, 2010.

38 SOUZA FILHO, M.S.M.; LIMA, J.R.; NASSU, R.T.; BORGES, M.F. Avaliação físico-química e sensorial de néctares de frutas nativas da Região Norte e Nordeste do Brasil: estudo exploratório. Brazilian Journal of Food Technology, v.5, p.139-143, 2002.

39 SOUZA, C.N. Características físicas, físico-químicas e químicas de três tipos de jenipapos (Genipa americana L.). 2007. 72 f. Dissertação (Mestrado em Produção Vegetal) - Universidade Estadual de Santa Cruz, Ilhéus, 2007.

40 STONE, H.; SIDEL, J.L. Sensory evaluation practices. $2^{\text {nd }}$ ed. Redwood City, California: Academic Press, 1993. $338 \mathrm{p}$.

41 UNITED STATES DEPARTMENT OF AGRICULTURE (USDA). National nutrient database for standard reference. $22^{\text {th }}$ ed. 2009. 22 p.

\section{AGRADECIMENTOS}

Os autores agradecem à Fundação de Amparo à Pesquisa do Estado de Minas

Gerais (FAPEMIG) pelo suporte financeiro. 